\title{
Effect of Gibberellic Acid on Ripening of Strawberry Fruits (Fragaria annanassa Duch.)
}

\author{
G. A. Martínez, A. R. Chaves, ${ }^{*}$ and M. C. Añón
}

Centro de Investigación y Desarrollo en Criotecnología de Alimentos (CIDCA), Facultad de Ciencias Exactas, Universidad Nacional de La Plata, Consejo Nacional de Investigaciones Científicas y Técnicas, 47 y 116, (1900) La Plata, Argentina

Received November 29, 1993; accepted March 16, 1994

\begin{abstract}
Effect of $\mathrm{GA}_{3}$ on postharvest ripening in strawberry fruit was evaluated through different biochemical parameters. Strawberry slices at different ripening stages were incubated with $\mathrm{GA}_{3}$. A significant decrease on respiratory activity depending on $\mathrm{GA}_{3}$ concentration was obtained. Also $\mathrm{GA}_{3}$ was applied to whole and deachened fruit at white and green ripening stages. Our results show that $\mathrm{GA}_{3}$ has an inhibitory effect on strawberry fruit ripening, evidenced by a decrease in the respiratory activity and a delay in anthocyanin synthesis and chlorophylls degradation.
\end{abstract}

Regulation of ripening is fairly known in climacteric fruits in which ethylene plays a key role as a ripening promotor. In contrast, ethylene has only a minor effect in nonclimacteric fruits like strawberry (Given et al. 1988a, Abeles and Takeda 1990). At present, hormonal regulation of strawberry fruit ripening is not fully understood. It has been demonstrated that the achenes produce the key hormones responsible for fruit ripening (Nitsch 1950). These hormones are probably auxins. They speed up the receptacle growth during the early stages of the development process (Southwick and Poovaiah 1987). During later stages of ripening, these hormones produce a decrease in the activity of phenylalanine ammonia-lyase (PAL, E.C.4.3.1.5), which, in turn, result in a decrease in the amount of anthocyanin. Auxins also lead to a delay in chlorophylls degradation (Given et al. 1988a,b,c). The role of gibberellins in the regulation of fruit ripening has also been the subject of a number of studies. It has been observed that gibberellic acid $\left(\mathrm{GA}_{3}\right)$ causes a delay in

* Author for correspondence. ripening. Application of $\mathrm{GA}_{3}$ delayed chlorophyll degradation in citrus (Biale 1978, Abdel-Gawad and Romani 1974) and mango fruits (Khader et al. 1988). $\mathrm{GA}_{3}$-induced reduction in amylase and peroxidase activities were also observed in mango fruits (Khader et al. 1988). $\mathrm{GA}_{3}$ also delayed the softness and color change in cherries (Facteau et al. 1985). The respiratory climateric was inhibited by $\mathrm{GA}_{3}$ application in apricot (Abdel-Gawad and Romani 1974) and tomato (Babbitt et al. 1973) fruits. The object of this study was to examine the effect of exogenously applied $\mathrm{GA}_{3}$ on strawberry fruits harvested during the early stages of ripening. The effect of $\mathrm{GA}_{3}$ were evaluated by measuring $\mathrm{CO}_{2}$ production and detecting changes in pigment levels (chlorophylls and anthocyanins).

\section{Materials and Methods}

\section{Plant Material and $\mathrm{GA}_{3}$ Application}

Strawberries used (Fragaria annanassa, Duch, Selva) were representative of different ripening stages and were obtained from local producers. Fruits were classified depending on external color: green, white, and 25\% red. A green fruit is defined as one that has completed its growth but has not yet changed its color, a white fruit has just started its color change, and a $25 \%$ red fruit is one which has $25 \%$ of its surface with red color. The fruits were thoroughly washed with water, then with a $1 \% \mathrm{NaClO}$ solution and, finally, three times with sterilized distilled water. Subsequently, they were dried under a laminar flow in sterile conditions. For certain experiments, achenes were removed using sterilized tweezers. Sterile solutions of $1,0.5$, and $0.25 \mathrm{mM}$ $\mathrm{GA}_{3}$ in $0.053 \mathrm{M}$ citric buffer, $0.094 \mathrm{M} \mathrm{Na}_{2} \mathrm{PO}_{4} \mathrm{H}$ adjusted to $\mathrm{pH}$ 4.5 , containing $2 \%$ dimethylsulfoxide (DMSO) were applied to whole fruit with cotton swabs. Treated fruits were placed in trays, covered with a polyolefinic film microperforated with 2 holes $\left(6.25 \mathrm{~cm}^{2}\right)$ per square inch and incubated in the dark at $20^{\circ} \mathrm{C}$ for 3 days. Samples were collected periodically and stored at $-70^{\circ} \mathrm{C}$ until analysis. 


\section{Determination of Respiratory Activity}

Strawberry slices, 2-3 mm thick, were cut horizontally from the central part of the fruit. Three or four slices (approximately $2 \mathbf{g}$ ) were placed in hermetically sealed flasks, containing approximately $5 \mathrm{ml}$ of sterile solutions of $0.053 \mathrm{M}$ citric buffer, $0.094 \mathrm{M}$ $\mathrm{Na}_{2} \mathrm{PO}_{4} \mathrm{H}$ (pH 4.5) with $0-0.5 \mathrm{mM}$ of $\mathrm{GA}_{3}$. The flasks were incubated in the dark at $20^{\circ} \mathrm{C}$ for 3 days. Gas samples were extracted periodically, and the level of $\mathrm{CO}_{2}$ concentration measured. The analysis was performed in a Shimadzu GC-6A model gas chromatograph equipped with silica gel and molecular sieve $5 \mathrm{~A}$ columns and a thermal conductivity detector. The carrier gas was $\mathrm{H}_{2}$. Respiratory activity was expressed as microliters of $\mathrm{CO}_{2}$ produced per gram of tissue per hour.

\section{Extraction and Estimation of Pigment Content}

Anthocyanins. Frozen fruits were ground to fine powder and a portion $(0.3 \mathrm{~g})$ was extracted in $3 \mathrm{ml}$ of methanol containing $1 \%$ $\mathrm{HCl}$, stirred and centrifuged $(2000 \mathrm{~g}, 15 \mathrm{~min})$ at $4^{\circ} \mathrm{C}$. Supernatant anthocyanin concentration as pelargonidin 3-glucoside, was determined in a Shimadzu spectrophotometer UV 150-02 at $510 \mathrm{~nm}$ using a molar absortivity coefficient of $36000 \mathrm{~V} / \mathrm{cm}$.mol (Woodward 1972).

Chlorophyll. Frozen fruits were ground to fine powder and a $500-\mathrm{mg}$ portion was extracted in $5 \mathrm{ml}$ of acetone at $-20^{\circ} \mathrm{C}$, stirred, and centrifuged $(2000 \mathrm{~g}, 15 \mathrm{~min})$ at $4^{\circ} \mathrm{C}$. The concentration of chlorophylls was determined spectrophotometrically at 645, 652, and $663 \mathrm{~nm}$ (Bruinsma 1963).

\section{Results Analysis}

Experiments were performed at least three times. Respiratory activity experiments were carried out with three to four slices in each flask, with three replications for each hormone concentration. Experiments for estimation of pigment content were performed with, at least, 20 fruits for each hormone concentration. Variance analysis (ANOVA) was used for statistical data evaluation. Mean comparison was determined with the Least Significant Difference (LSD) test at a significance level $(\alpha)$ of 0.05 .

\section{Results and Discussion}

Numerous biochemical and physiological changes take place during fruit ripening. The production of ATP and other energy-rich component in ripening is provided by the respiration process. Thus, a higher rate of respiratory level is associated with a higher rate of ripening. In the present work the respiratory activity of strawberry fruit slices was evaluated at green, white, and $25 \%$ red stages of ripening during 3 days of incubation as described in the Materials and Methods section. Results are shown in Fig. 1. A statistical decrease of respiratory activity was ob-

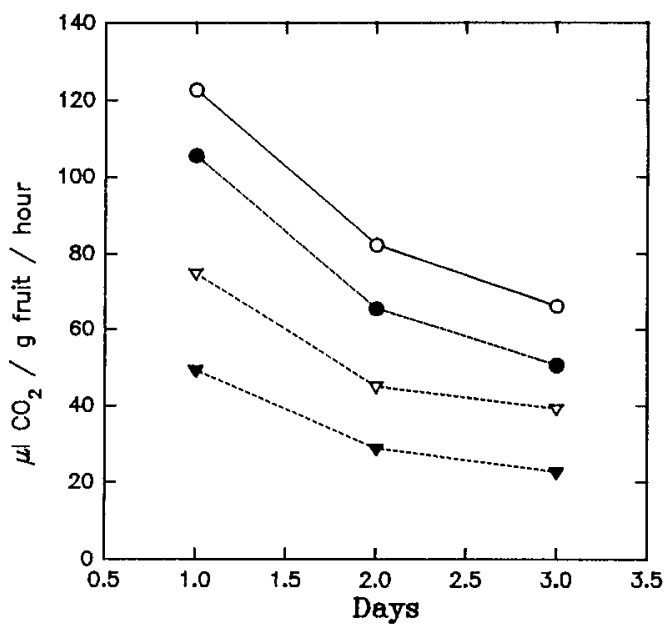

Fig. 1. Respiratory activity of strawberry slices from fruits harvested at different stages of ripening. Slices were incubated in the dark for 3 days at $20^{\circ} \mathrm{C}$ in $0.053 \mathrm{M}$ citric buffer, $0.094 \mathrm{M}$ $\mathrm{Na}_{2} \mathrm{PO}_{4} \mathrm{H}$ adjusted to $\mathrm{pH}$ 4.5. $\mathrm{LSD}_{0.05}=10.3 . \mathrm{O}=$ green, $\mathrm{O}=$ white, $\nabla=25 \%$ red, $\nabla=25 \%$ red treated with $0.5 \mathrm{mM} \mathrm{GA}_{3}$.

served during storage. It corresponded to a decrease of $35-40 \%$ from the first to the second day of incubation and another $15-20 \%$ from the second to the third day of incubation. Moreover, $\mathrm{CO}_{2}$ production decreased with the ripening stage evidencing a lower metabolic activity.

The effect of $\mathrm{GA}_{3}$ on the respiratory activity was also studied. Hormones commonly have a physiological effect in the range of $10^{-5}$ to $10^{-9} \mathrm{M}$. However, when hormones are used for technological purposes, for instance to regulate fruit ripening, they are applied at higher concentrations: $10^{-4}$ to $10^{-5} \mathrm{M}$ (Ben-Arie and Ferguson 1990, Facteau et al. 1985, Hinderer et al. 1984, Ben-Arie et al. 1986). These high concentrations are necessary in part to assure an adequate diffusion into the tissue and overcome effects of degradation. Considering this fact and in order to analyze the feasibility of the application of $\mathrm{GA}_{3}$ to regulate the rate of strawberry ripening, we decided to study the effect of the hormone at the $10^{-4}$ to $10^{-5} \mathrm{M}$ level. The respiratory activity of strawberry slices corresponding to ripening stage of $25 \%$ red incubated with $0.5 \mathrm{mM} \mathrm{GA}_{3}$ is shown in Fig. 1. This treatment leads to a decrease of $\mathrm{CO}_{2}$ production compared to the control at the same ripening stage. It was also verified that the rate of inhibition was approximately constant during the incubation period. Similar results (not shown) were obtained for white and green fruit.

The effect of different levels of gibberellic acid on respiratory activity was analyzed by computing the ratio between the respiratory activities of slices treated with $\mathrm{GA}_{3}(\mathrm{C})$ and control slices without $\mathrm{GA}_{3}$ 


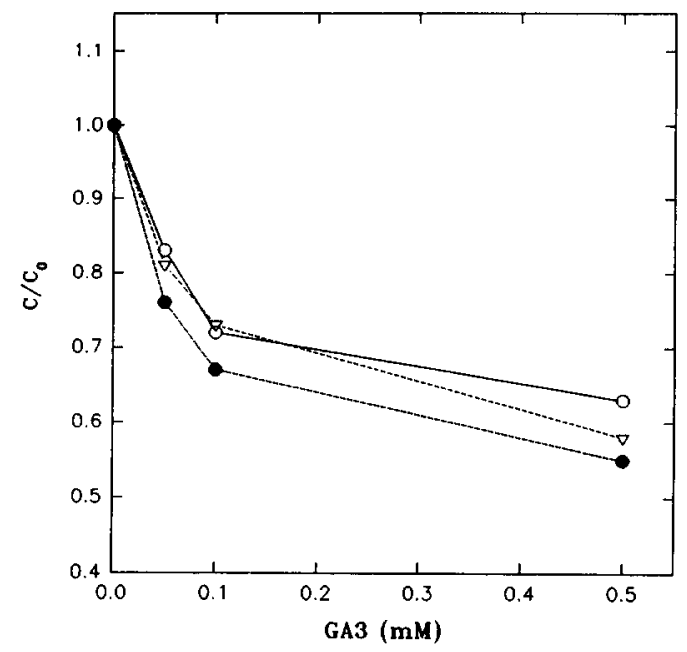

Fig. 2. Effect of $\mathrm{GA}_{3}$ concentrations on the ratio between the respiratory activities of slices treated with $\mathrm{GA}_{3}(\mathrm{C})$ and control slices without $\mathrm{GA}_{3}(\mathrm{Co})$ in the same period. Strawberry slices obtained from fruits harvested at different stages of ripening and incubated in the dark for 3 days at $20^{\circ} \mathrm{C}$ in $0.053 \mathrm{M}$ citric buffer, $0.094 \mathrm{M} \mathrm{Na}_{2} \mathrm{PO}_{4} \mathrm{H}$ adjusted to $\mathrm{pH}$ 4.5. $\mathrm{LSD}_{0.05}=0.156 . \mathrm{O}=$ green, $=$ white, $\nabla=25 \%$ red.

(Co) in the same period. As shown in Fig. 2, increasing amounts of $\mathrm{GA}_{3}$ led to a decrease in $\mathrm{CO}_{2}$ production. A $30 \%$ decrease of respiratory activity was obtained at a concentration of $0.1 \mathrm{mM}$ of $\mathrm{GA}_{3}$. The dose-response curve was nonlinear and tended to level off at higher $\mathrm{GA}_{3}$ concentrations. This suggested a saturation of $\mathrm{GA}_{3}$ receptor at high- $\mathrm{GA}_{3}$ levels. However, it should be mentioned that the effects observed may be a useful pharmacological effect of supraoptimal levels of $\mathrm{GA}_{3}$ not entirely related to any physiological effect. When the effect of different $\mathrm{GA}_{3}$ concentrations on the respiratory activity of strawberry slices at different ripening stages was analyzed, it was found that the inhibitory effect of the hormone was similar for all stages (Fig. 2).

Loss of chlorophylls associated with degradation and/or synthesis of anthocyanins are useful parameters to investigate the fruit ripening process. We examined the effect of $\mathrm{GA}_{3}$ on pigments content of whole strawberry fruits. Figure 3 shows a photograph of strawberry fruits nontreated and treated with $\mathrm{GA}_{3}(1 \mathrm{mM})$ and incubated at $20^{\circ} \mathrm{C}$ for 3 days as described in Materials and Methods. $\mathrm{GA}_{3}$ delayed the ripening of treated fruits compared with the control fruits. The color change was more evident in nontreated fruits. The anthocyanin and chlorophyll contents of control and $\mathrm{GA}_{3}$-treated strawberry fruits were measured during the course of 3 days incubation at $20^{\circ} \mathrm{C}$. Normally, green fruits increased their anthocyanin contents after the third

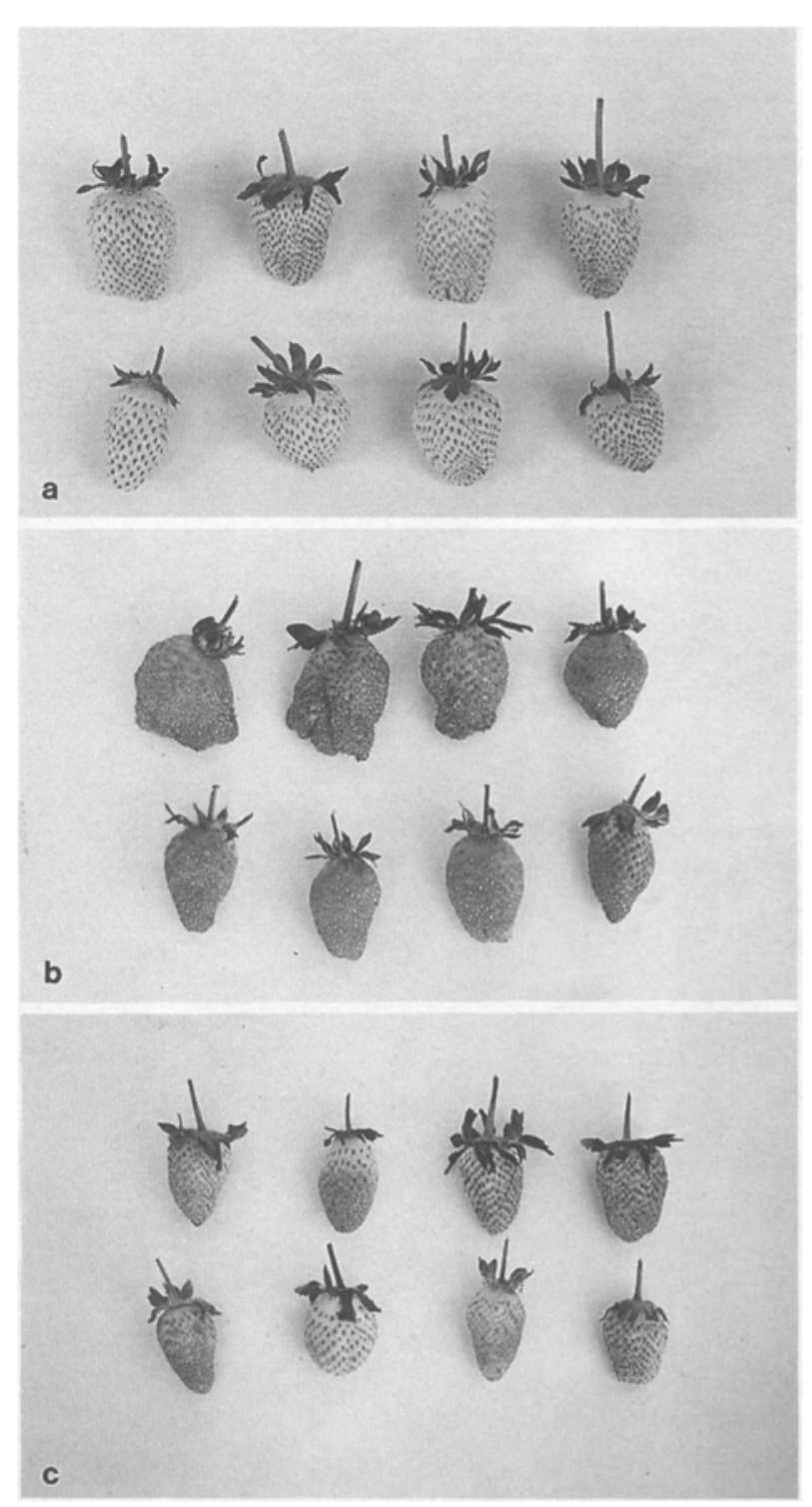

Fig. 3. Photograph of white strawberries at harvest (a), white strawberries nontreated (b), and treated with $\mathrm{GA}_{3} 1 \mathrm{mM}$ (c). Both (b and $\mathbf{c}$ ) were incubated for 3 days at $20^{\circ} \mathrm{C}$ as described in Materials and Methods.

day of incubation reaching $50-75 \%$ of the surface red color, while white fruits increased their anthocyanin contents after the third day of incubation reaching $75-100 \%$ of the surface red color (Table 1 ). In accordance with other authors (Given et al. 1988a, Cheng and Patrick 1991), a marked increase in anthocyanin concentration was observed during the last stage of ripening. Exogenous application of $\mathrm{GA}_{3}$ caused a delay in anthocyanin production of 30-35\% (Fig. 4a). This effect was statistically significant at the second and third days of incubation. The same effects were observed for both ripening 
Table 1. Effect of incubation for 3 days at $20^{\circ} \mathrm{C}$ on the levels of anthocyanins and chlorophylls in strawberry fruit

\begin{tabular}{|c|c|c|c|c|c|c|}
\hline \multirow[b]{2}{*}{ Fruit stage } & \multicolumn{2}{|c|}{ Anthocyanins $^{\mathrm{a}}$} & \multicolumn{2}{|c|}{ Chlorophyll $\mathrm{a}^{\mathrm{b}}$} & \multicolumn{2}{|c|}{ Chlorophyll b ${ }^{b}$} \\
\hline & Day 0 & Day 3 & Day 0 & Day 3 & Day 0 & Day 3 \\
\hline Green & $6.0 \pm 0.4$ & $83 \pm 14$ & $10.5 \pm 0.6$ & $4.3 \pm 0.3$ & $4.1 \pm 0.7$ & $2.6 \pm 0.2$ \\
\hline White & $8.2 \pm 1.2$ & $280 \pm 24$ & $7.6 \pm 1.1$ & $2.7 \pm 0.2$ & $2.6 \pm 0.2$ & $1.0 \pm 0.1$ \\
\hline
\end{tabular}

a Expressed as nanomoles of anthocyanins per gram fresh weight $\pm \sigma$.

${ }^{b}$ Expressed as micrograms of chlorophyll per gram fresh weight $\pm \sigma$.

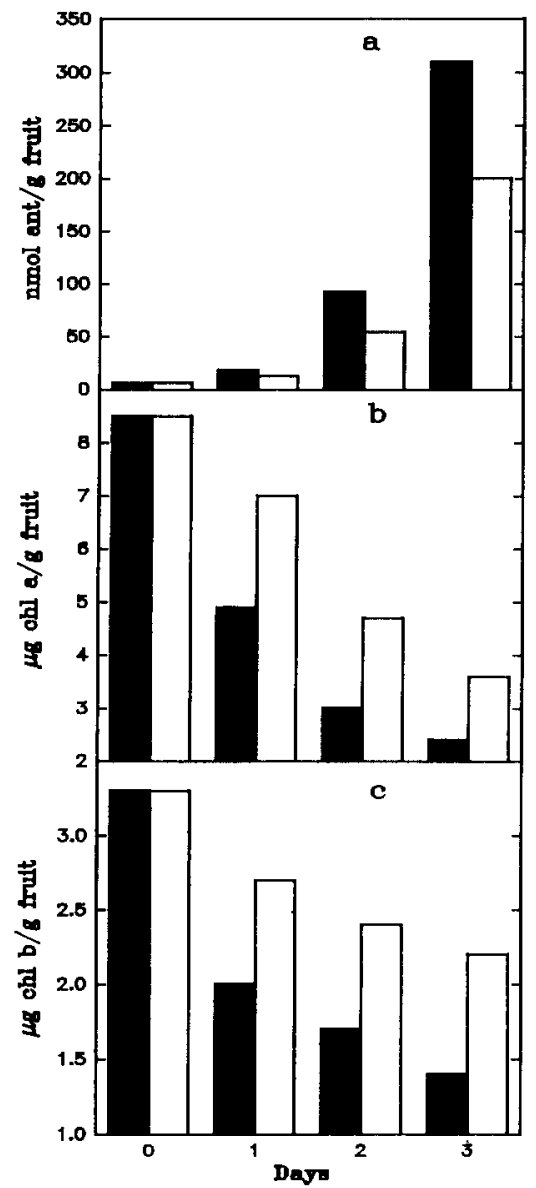

Fig. 4. Changes in pigment content of white strawberry fruits nontreated and treated with $1 \mathrm{mM} \mathrm{GA}_{3}$ and incubated for 3 days at $20^{\circ} \mathrm{C}$. (a) Anthocyanins. $\mathrm{LSD}_{0.05}=8.31$ (b) chlorophyll a. $\mathrm{LSD}_{0.05}=0.23$ (c) chlorophyll b. $\mathrm{LSD}_{0.05}=0.13 . \square=$ nontreated, $\square=$ treated.

stages used as starting plant material: white and green fruit. Similar effects were reported by other authors working with different systems. $\mathrm{GA}_{3}$ was found to delay color production and anthocyanin synthesis in cherries (Facteau et al. 1985), and to stop the anthocyanins synthesis at chalcone synthase and PAL level in cellular cultures of carrots (Hinderer et al. 1984).

At the same time, during ripening a disorganiza- tion of the chloroplast occurs and consequently, chlorophyll degrades. Working under the same condition described for anthocyanin studies, nontreated green and white fruits decreased their chlorophylls contents as shown in Table 1. Exogenous treatment with $\mathrm{GA}_{3}$ caused a delay in the degradation of chlorophylls, both Chl a (Fig. 4b) and Chl b (Fig. 4c). In control and $\mathrm{GA}_{3}$-treated fruits, the degradation rate of $\mathrm{Chl}$ a was higher than the one of $\mathrm{Chl}$ b. However, the inhibition produced by $\mathrm{GA}_{3}$ was the same for both kinds of chlorophylls. This $\mathrm{GA}_{3}$ inhibition was statistically significant from the first day of incubation. As occurred for anthocyanins, inhibition of chlorophylls degradation was observed in both green and white fruit. The effect of $\mathrm{GA}_{3}$ on chlorophyll degradation has been studied by Khader et al. (1988) on climacteric fruit such as mangos and by Biale (1978) on nonclimacteric fruit such as citrics. In both cases $\mathrm{GA}_{3}$ reduced chlorophylls degradation, similar to the effect described here.

On the assumption that achenes produce auxins (Nitsch 1950, Southwick and Poovaiah 1987) a series of experiments were performed in which fruit were deachened in order to evaluate the effect of removing that source of auxin and subsequent interference. $\mathrm{GA}_{3}$ was applied as described previously for the whole fruit experiments. Control fruits were also deachened. Results were similar to those obtained before. The synthesis of anthocyanin was inhibited by $30-35 \%$ and the degradation of chlorophyll $a$ and $b$ was delayed in deachened and $\mathrm{GA}_{3}$ treated fruit compared to deachened control fruit. A remarkable aspect of these observations was that assayed concentrations of $\mathrm{GA}_{3}(0.25-1 \mathrm{mM})$ led to the same inhibitory effect, and no significant differences were found.

We conclude that application of $\mathrm{GA}_{3}$ results in an inhibition of the general metabolic activity, evidenced through a decrease in the respiratory activity of the three ripening stages assayed. Postharvest application of $\mathrm{GA}_{3}$ inhibited $30-35 \%$ the color development of green and white fruit; it also delayed chlorophylls $a$ and $b$ degradation. This inhibitory activity of $\mathrm{GA}_{3}$ can take place in the presence and/ or absence of the hormone produced by the 
achenes. It is likely that, $\mathrm{GA}_{3}$ may be acting in some way on the enzymes thought to be involved in this process.

Acknowledgments. G. A. Martínez is a fellow of the Consejo Nacional de Investigaciones Científicas y Tecnicas (CONICET) de la República Argentina. A. R. Chaves and M. C. Añon are members of the Research Career of the Consejo Nacional de Investigaciones Científicas y Tecnicas (CONICET) de la República Argentina. This work was supported by grants from CONICET

\section{References}

Abdel-Gawad H, Romani RJ (1974) Hormone-induced reversal of color change and related respiratory effects in ripening apricot fruits. Physiol Plant 32:161-165

Abeles FB, Takeda F (1990) Cellulase activity and ethylene in ripening strawberry and apple fruit. Sci Hort 42(4):269275

Babbitt JK, Powers MJ, Patterson ME (1973) Effects of growthregulators on cellulase, polygalacturonase, respiration, color and texture of ripening tomatoes. J Amer Soc Hort Sci 98(1):77-81

Ben-Arie R, Bazak H, Blumenfeld A (1986) Gibberellin delays harvest and prolongs storage life of persimmon fruits. Acta Hort 179:807-813

Ben-Arie R, Ferguson IB (1990) Ethylene production by growing and senescing pear fruit cell suspensions in response to gibberellin. Plant Physiol 95:943-947

Biale JB (1978) On the interface of horticulture and plant physiology. Ann Rev Plant Physiol 29:1-23
Bruinsma J (1963) The quantitative analysis of chlorophylls a and b in plants extracts. Photochem Photobiol 2(2):241-249

Cheng GW, Patrick JB (1991) Activity of Phenylalanine Ammonia-Lyase (PAL) and concentration of anthocyanins and phenolics in developing strawberry fruit. J Amer Soc Hort Sci 116(5):865-869

Facteau TJ, Rowe KE, Chestnut NE (1985) Firmness of sweet cherry fruit following multiple applications of gibberellic acid. J Amer Soc Hort Sci 110(6):775-777

Given NK, Venis NA, Grierson D (1988a) Hormonal regulation of ripening in the strawberry, a non-climateric fruit. Planta 174:402-406

Given NK, Venis NA, Grierson D (1988b) Phenylalanine Ammonia-Lyase activity and anthocyanins synthesis in ripening strawberry fruit. J Plant Physiol 133:25-30

Given NK, Venis NA, Grierson D (1988c) Purification and properties of Phenylalanine Ammonia-Lyase from strawberry fruit and its synthesis during ripening. J Plant Physiol 133: 31-37

Hinderer W, Petersen M, Seitz HV (1984) Inhibition of flavonoid biosynthesis by gibberellic acid in cell suspensions cultures of Daucus carota L. Planta 160:544-549

Khader SESA, Singh BP, Khan SA (1988) Effect of $\mathrm{GA}_{3}$ as a post-harvest treatment of mango fruit on ripening, amylase and peroxidase activity and quality during storage. Sci Hort 36:261-266

Nitsch JP (1950) Growth and morphogenesis of the strawberry as related to auxin. Am J Bot 37:211-215

Southwick SM, Poovaiah BW (1987) Auxin movement in strawberry fruit corresponds to its growth-promoting activity. Amer Soc Hort Sci 112(1):139-142

Woodward JR (1972) Physical and chemical changes in developing strawberry fruits. J Sci Food Agric 23:465-473 